Otterbein University

Digital Commons @ Otterbein

Health and Sport Sciences Faculty Scholarship

Health and Sport Sciences

3-2014

\title{
Why Hospital Improvement Efforts Fail: A View From the Front Line.
}

Paul D. Longenecker

Otterbein University

Clinton O. Longenecker

University of Toledo

Follow this and additional works at: https://digitalcommons.otterbein.edu/hsports_fac

Part of the Health and Medical Administration Commons

\section{Repository Citation}

Longenecker, Paul D. and Longenecker, Clinton O., "Why Hospital Improvement Efforts Fail: A View From the Front Line." (2014). Health and Sport Sciences Faculty Scholarship. 2.

https://digitalcommons.otterbein.edu/hsports_fac/2

This Article is brought to you for free and open access by the Health and Sport Sciences at Digital Commons @ Otterbein. It has been accepted for inclusion in Health and Sport Sciences Faculty Scholarship by an authorized administrator of Digital Commons @ Otterbein. For more information, please contact

digitalcommons07@otterbein.edu. 


\section{Why Hospital Improvement Efforts Fail: A View From the}

\section{Front Line}

Clinton O. Longenecker, PhD, Stranahan Professor Leadership and

Organizational Excellence, Department of Management, College of Business and

Innovation, University of Toledo, Ohio, and Paul D. Longenecker, RN, PhD,

Senior Instructor, Department of Health and Sport Sciences, School of Professional

Studies, Otterbein University, Westerville, Ohio

\section{EXECUTIVE SUMMARY}

In the 21st century, healthcare executives are facing changes of unprecedented magnitude in virtually every area, affecting their ability to compete. That hindrance brings with it a greater need for rapid and effective organizational change and improvement. Yet changes in the U.S. healthcare delivery system have historically been criticized as slow and less than effective in responding to the changes necessary for rapid performance improvement. To that end, the purpose of this applied research study was to help healthcare executives better understand the 
barriers to effective organizational change and improvement from the perspective of frontline leaders. Focus groups were conducted with 167 frontline leaders from four community hospitals to explore why hospital change efforts fail. Participants representing 11 different functional areas, including all facets of hospital operations, were asked to identify the primary causes of failure of a recent change initiative at their hospital. A content analysis of the focus group data identified 10 primary barriers to successful hospital change, some of which are ineffective implementation planning and overly aggressive timelines, failure to create project buy-in and ownership, ineffective leadership and lack of trust in upper management, unrealistic improvement plans, and communication breakdowns. Leadership lessons and recommendations based on the research findings are provided.

\section{[BOX]}

For more information about the concepts in this article, contact Dr. Clinton Longenecker at Clinton.Longenecker@utoledo.edu.

[end BOX] 


\section{INTRODUCTION}

To say that hospitals and healthcare systems are in the midst of revolutionary change is an understatement. In the 21st century, healthcare executives are facing changes of unprecedented magnitude in virtually every area, affecting their ability to compete (ACHE, 2011). These changes range from new government policy and regulation to technological breakthroughs to the demand for cost containment to the search for new sources of revenue to dealing with talent shortages, as well as a wide variety of human resource issues (Dye, 2010; McAlearney, 2010). And all the while, most organizations in the United States are dealing with an abnormal increase in volume that brings with it a greater need for rapid, ongoing, and effective organizational change and improvement.

Traditionally, medicine, technology, and reimbursement have been the primary drivers of change in the healthcare delivery system (Bazzoli, Dynan, Burns, \& Yap, 2004). Now, new laws, rules, and regulations associated with the Affordable Care Act (PPACA) have become the drivers of the healthcare revolution. Open up any current healthcare or business publication, and you are immediately bombarded with eye-popping headlines, dire predictions, and data suggesting that the time for healthcare change, improvement, and transformation is now. Yet changes in the healthcare delivery system are criticized as slow and less than effective in responding to the changes necessary for rapid performance improvement (Bazzoli et al., 2004).

For the past 30 years, we have been involved in both the practice of healthcare delivery and research on large-scale organizational change and improvement. We have found that a key set of components needs to be in place for an organization to implement successful change and improvement on an ongoing basis (Longenecker, Papp, \& Stansfield, 2007, 2009). Healthcare 
leaders must foster an organizational culture that embraces and enacts these critical, fundamental practices with passion and acumen. When organizational leaders do not create such a culture, change and improvement efforts are problematic.

But why specifically do current organizational change and improvement efforts in healthcare often fail to deliver desired outcomes? Rather than approach this question from the perspective of senior leaders who create healthcare strategy, policy, and structure, we sought the perspective of frontline leaders responsible for actually implementing the myriad changes that are becoming part of the increasingly large healthcare fabric.

Thus, the purpose of this applied research study is to help healthcare executives better understand the factors that allow real, rapid change and improvement to take place by better understanding the needs of frontline healthcare leaders. A quote from one frontline nursing supervisor who participated in our study helps underscore the importance of this research effort:

It is hard to get around the fact that our hospital has to improve much faster than it has in the past if we are to make it in the future.... One of the big problems we face in trying to deal with all this is that we don't always do the things necessary to make change really happen; we are always rushing, plans can be half baked, and there is usually a gap between what our top administrators want to have happen and what we are up against on the floor... We spend a lot of time going backwards to try and make changes and fix things when we could have done it better the first time.

\section{METHODS}


To explore the barriers to effective organizational change and improvement in the healthcare industry, we conducted focus groups with 167 frontline leaders from four Midwest community hospitals as part of a formal leadership development experience that we led. The four participating organizations were nonprofit entities; ranged in size from 197 to 294 beds, with an average of 238 beds; and were secondary care hospitals. For purposes of this study, a frontline leader is defined as a member of the organization's management team with direct supervisory responsibility over employees who deliver the organization's services (Longenecker \& Simonetti, 2001). The frontline leader participants in this study were $61 \%$ female and $39 \%$ male with an average age of 37.9 years. They represented 11 functional areas of their hospitals: $68.3 \%$ were from clinical operations (nursing, respiratory therapy, physical therapy, pharmacy, labs, and transportation), and 31.7\% were from business operations (front office services, information systems, facilities, security, and food services).

In Part 1 of the study, participants were asked the following question individually:

Based on your experience, please identify a recent organizational change/improvement effort that was ineffective in that it did not produce the results/outcomes that were desired by your organization. Please describe in specific detail why this effort was ineffective.

Upon completion of this task, participants were assigned to four-person focus groups to discuss and compare their individual observations and experiences as a team. All members of a particular focus group were from the same hospital, and every effort was made to ensure that each group represented a cross-section of frontline leaders from different parts of the organization to offer a variety of perspectives on each failed organizational change effort jhm 59.2_Longenecker article 
discussed. Once assigned, each team was given written guidelines instructing each person to share his or her individual findings with the group, encourage equal participation, and encourage each group to work toward consensus around the top 10 factors that caused the target improvement efforts to fail.

Following these discussions, each team was asked to provide the facilitator with the group's top 10 list. The 42 focus groups generated, on average, 9.85 factors, which were then content analyzed using a three-judge review panel to review and assign each focus group's factors to an appropriate cause-of-failure category. The three judges were seasoned organizational development professionals with previous experience in this type of qualitative research analysis. It is important to note that these categories were not predetermined but rather emerged as the content analysis proceeded. For a factor to be assigned to a specific category, two out of three judges had to independently agree that a factor belonged in a particular failure category.

In all, focus groups identified more than 20 different factors that participants believed cause hospital organizational change and improvement efforts to fail. Figure 1 contains the 10 most frequently mentioned factors, with corresponding percentages and ranked in order of frequency. The findings in the figure are the basis for the forthcoming discussion and recommendations.

\section{[FIGURE 1 about here]}

\section{FINDINGS}

In this section, we outline the top 10 key factors that cause hospital improvement and change efforts to fail based on the input of the study participants. We include verbatim quotes when a 
statement or comment was taken directly from the information provided by the focus groups. In addition, a key leadership lesson from each factor is identified.

\section{Key Factor 1: Poor Implementation Planning and Overly Aggressive Timelines}

According to the participants in the study, change initiatives in healthcare organizations fail to achieve desired outcomes because of their implementation is poorly planned and the proposed time frames for implementation are overly aggressive. These two issues were consistently linked by participants and were identified as the single greatest cause for failure. This finding is not surprising given the economic and legislative pressures being brought to bear on hospitals coupled with the depth and breadth of changes sweeping the healthcare industry. Nonetheless, participants made clear that there is no substitute for taking the time to develop an effective plan for the implementation of any organizational change.

One major reason for poor implementation planning was that organizations frequently set unrealistic deadlines. Ambitious schedules can be established, but they must be tempered with the reality that implementation planned for an unduly short time frame can short-circuit the change process and cause leaders to "jump from having an idea or plan for improvement directly to implementation," with negative outcomes. One team captured the essence of this discussion as "bad planning plus unrealistic deadlines = failure."

Leadership lesson: There is no substitute for taking the time to properly plan for the implementation of any desired change or improvement initiative. Without proper implementation, critical resources can be wasted without producing a tangible positive outcome. 


\section{Key Factor 2: Failing to Create Buy-in for/Ownership of the Initiative}

Participants provided myriad examples in their focus groups describing how change and improvement efforts failed because of a clear lack of, in their words, frontline "buy-in," “empowerment," “engagement," “participation," and “ownership." A strong sense emerged from the discussions that hospital frontline personnel were frequently not included in important discussions and decisions surrounding how change initiatives might be rolled out to the organization. It was made clear that this lack of effort to "create buy-in" and "ownership from frontline personnel" demotivated, disenfranchised, and disenchanted the very people who were most necessary for effective implementation of any change or improvement initiative.

Regardless of the nature of change, participants stated that without such buy-in and ownership, frontline personnel are less likely to be committed to the change and take the steps necessary to ensure that the change will be implemented properly to achieve desired outcomes. Participants added that this lack of buy-in is frequently driven by the fact that senior leaders have failed to make a strong case or provide a solid explanation for the necessity of the upcoming change. This "case for change" is critical, as frontline personnel need to know exactly why changes are being required and what the desired expectations and outcomes are.

Leadership lesson: Without input, buy-in, and ownership from the people responsible for making the change work, the likelihood of maximum performance diminishes significantly.

\section{Key Factor 3: Ineffective Leadership and Lack of Trust in Upper Management}


It is a well-worn axiom of organizational life that without effective leadership at all levels of the organization, real change or improvement is difficult at best to achieve. Participants frequently supported this position as they made it clear that, more than $60 \%$ of the time, ineffective leadership was a primary cause of an inadequate effort involving change in performance improvement. When people do not trust their leaders, whether the issue is character or competency, people are unlikely to provide maximum effort. When ineffective leaders attempt to implement change, their lack of credibility and trustworthiness provides their employees with a ready-made reason to not fully engage in these efforts.

Study participants noted that in hospital/healthcare environments, leaders can ill afford to be viewed as, in their words, "bureaucrats," "leading from behind," "sycophants," "politicos," or "butt-kissers." According to these participants, ineffective leadership becomes even more counterproductive in periods of rapid change that demand increased performance.

Leadership lesson: To achieve maximum performance improvement from any change initiative, leaders must demonstrate competence and character, and they must lead by example.

\section{Key Factor 4: Failing to Create a Realistic Plan or Improvement Process}

It is interesting to note that two of the first four factors that drive failure clearly fall into the category of leaders being ineffective in laying out a plan of action that will lead to a desired outcome. It is commonly stated that "failing to plan is planning to fail," and the study participants clearly agree. With hospitals under increasing pressure to make rapid changes and improvements to their operations, their senior leaders are quick to move forward with plans that were described by participants as frequently "unrealistic," "incomplete," "overly 
optimistic," "half-baked," "unworkable," "impractical," and even "naïve." When leaders do not take the time to create effective action plans or processes for desired changes, they often lose on several counts, according to study participants. First, they waste precious time and resources in pursuing change using plans that have not been thoroughly and realistically thought out.

Second, the outcomes associated with the activity are almost always negative or, at a minimum, are less than optimal. Third, the credibility, common sense, and trustworthiness of senior leaders are quickly called into question at a time when they need all the support that they can get to move their organizations forward.

It has been said that any change worth making is worth making right. Our study's participants indicated that to make change right requires an effective, realistic plan and an improvement process that has been thoroughly considered and vetted prior to implementation.

Leadership lesson: When leaders ask members of their organization to implement a change initiative, it is imperative that sufficient effort, time, input, and resources have gone into the planning process.

\section{Key Factor 5: Ineffective and Top-Down Communication}

Communication is frequently a challenge in any large organization, but this is particularly true in periods of rapid change, as affirmed by study participants. Participants stated that a lack of effective two-way communication surrounding any change or improvement initiative causes significant problems for numerous reasons. When a change is being introduced, extensive and intense two-way communication is necessary among all parties involved. One of the primary reasons that employees frequently fail to buy into or take ownership of a change initiative is 
that they "do not fully understand either the reason for the change or the process" that will be used to improve performance.

One-way and top-down communication has the advantage of being quick and easy. But this approach brings with it the great disadvantage of failing to create a full understanding of what changes are coming, why they are important, the role that each individual plays in achieving a desirable outcome, and whether or not the message being sent is the message that is being received and understood. Study participants provided a variety of examples in which solid change initiatives could have provided positive outcomes if leaders had taken the time to effectively communicate the message and the process. In the words of one focus group, "It seems like we are in such a hurry all the time that it is easy to not communicate as well as we should ... and we only create problems for ourselves in doing so."

Leadership lesson: Any change initiative that is expected to produce superior outcomes needs superior, ongoing, two-way communication between those responsible for leading the change and those responsible for making the change happen.

\section{Key Factor 6: A Weak Case for Change, a Lack of Focus, and Unclear Desired Outcomes}

When any change initiative gets under way, leaders must make a clear-cut case for why the change is both necessary and important, clarify the focus of the change effort, and specify what desired outcome is needed for the change to be declared a success. Study participants again provided a wide range of examples of "change-for-change's-sake projects," "improvement projects without measurable or tangible metrics," "pet projects that were pushed forward 
without explanation or reason," "political change initiatives," and "feel-good projects" that may have had a good intention behind them but did little or nothing to improve performance.

A laboratory supervisor provided an excellent lesson to illustrate the importance of this finding: "If people are going to be asked to make changes, they need to know why they are being asked to change, who must do what differently, how [the changes] are going to be measured, and what success will look like." This leader did an excellent job of clarifying the importance of this discussion and defined a key finding. The why, who, how, and what must be clearly thought out by leaders and over communicated with those who must make the change happen for desirable outcomes to take place.

Leadership lesson: If leaders are serious about change, they must make a strong case for change, create clear focus on what needs to happen, and clearly articulate desired outcomes so participants know exactly what success will look like.

\section{Key Factor 7: Little or No Teamwork or Cooperation}

It was stated by one participant group that "healthcare is rapidly becoming the ultimate team sport," and this position was shared by a significant number of people in the study. Teamwork and cooperation are important in any organization, but in a hospital experiencing large-scale change, it becomes critically important, as shown by our findings. Participants made it clear that teamwork and cooperation are not natural by-products of hospital work life; they need the foundation of effective leadership and specific efforts aimed at "breaking down walls," "eliminating silos," "reducing self-interest," and "building cross-functionality." For improvement initiatives to be successful and to take hold rapidly, diverse groups must come 
together with a shared sense of purpose and vision to develop a plan or process that encourages and even motivates people to work together.

It is becoming increasingly difficult to solve a problem or improve a process in one part of a hospital without the new process affecting another part of the system - a phenomenon known as the law of unintended consequences. Leaders must take into account that activity in one area, viewed as improvement, might hinder the performance of another unit. Thus, it is important that they approach improvement with the team-based, problem-solving mind-set and introduce systems thinking into their efforts.

Leadership lesson: Teamwork and cooperation are critically important to an organization's ability to increase the likelihood of successful change and accelerate the change improvement process.

\section{Key Factor 8: Failing to Provide Ongoing Measurement, Feedback, and Accountability}

Any successful change effort is characterized by ongoing measurement feedback and accountability for action. Because of the magnitude and volume of changes taking place in hospitals, it is not uncommon to see leaders responsible for handling multiple change initiatives at any one time. A natural by-product of this flurry of activity is a lack of time available to establish and provide appropriate levels of ongoing measurement, feedback, accountability, and follow-up.

The focus groups discussed and made light of the fact that they were regularly engaged in change activities that frequently "disappeared," "fell through the cracks," "just went away," "died a slow death," or "were simply forgotten." All of these descriptions made it clear that 
those in charge of the change initiatives were not serious about delivering a real and tangible performance improvement or outcome. These practices were quick to elicit and breed "cynicism," "distrust," "skepticism," and "suspicion" on the part of the organization's members, who had been conditioned to not take these improvement efforts seriously. One team's description was apt: “Change efforts fail when leaders don't track progress or coach people daily." Ongoing measurement allows people to know that performance is observed, and that observation serves as a motivator. Ongoing feedback lets people know how well they are performing and what they need to do differently to improve. Finally, without enforcing accountability and providing follow-up, leaders send the message to their employees that the changes they have been asked to make are not important.

Leadership lesson: For a change effort to achieve a desired outcome, individuals and teams must receive ongoing measurement and feedback on their performance and be made accountable for progress.

\section{Key Factor 9: Unclear Roles, Goals, and Performance Expectations}

Whenever a change initiative is implemented, one of the first questions employees ask is, "How is this going to affect me?" According to study participants, change efforts become real when "people are told what they have to do differently," "employees are handed a new list of duties that make up their job," and "new goals and roles are rolled out." All of these points make clear that organizational change efforts must become "personal and/or individual" at some point if the change effort is to have its desired outcome. 
If individual employees are not being asked, encouraged, trained, and motivated to behave differently, there can be no real organizational improvement. While this statement may seem simplistic, participants in the focus groups emphasized that failure to clarify individual roles and performance expectations can be a major barrier to real organizational improvement.

Leadership lesson: Successful change efforts should always translate desired organizational performance outcomes into clearly defined roles, goals, and performance expectations for everyone involved in the change initiative.

\section{Key Factor 10: Lack of Time, Resources, and Upper-Management Support}

The final factor in the top-10 list falls into a category that described change as frequently taking place "on top of their day jobs." This is an important point because focus groups' descriptions of the change process frequently pointed to the fact that change was not necessarily viewed as "part of their job but rather something that they were being asked to do on top of their regular jobs." When frontline personnel are asked to make changes and the activity takes place on top of their regular work load, they endure additional stress, work, and, in some cases, hardship. Thus, study participants made it clear that change efforts will struggle when frontline personnel do not have sufficient time, resources (e.g., equipment, budget, training, access, staff), and support of top management in both word and deed. Without identifying, discussing, and addressing these support factors, frustration and failure can easily occur.

Leadership lesson: Real, successful change requires leaders to provide additional time, resources, and support. 


\section{DISCUSSION AND A CALL TO ACTION}

In his 1995 Harvard Business Review article entitled “Leading Change: Why Transformation Efforts Fail," John Kotter chronicled the factors that are necessary for an organization to experience successful change and transformation. His research reached the conclusion that real change and transformation take place when leaders manage the human dimensions of the change process with great care. Kotter emphasized that effective change requires a compelling vision with a sense of urgency, a meaningful and realistic plan that people understand, teamwork and empowerment, effective two-way communications, building on success to create momentum, and strong and effective leadership at every step of the process.

The key findings of our study strongly support Kotter's research and provide additional details on the dangers of unrealistic planning and timelines, failure to create buy-in and empowerment, one-way communications, lack of a compelling vision, little or no teamwork, lack of accountability, unclear performance expectations, and lack of top management support in hospital change efforts. The majority of the factors that cause hospital change to fail fall into the category of ineffective leadership and an absence of well-established and fundamental principles of change management. And while some of these problems have been previously noted by other researchers (Bazzoli et al., 2004; Cunningham et al., 2002; Capoccia \& Abeles, 2006), they now take on greater urgency in light of the hyper-dynamic healthcare landscape. The volume of real, successful change initiatives needed is only accelerating in healthcare settings. With the introduction and rollout of the numerous components of the ACA, healthcare leaders will need the buy-in and vested interest of their teams. Issues of access, quality, and cost are here to stay and are difficult to address without strong and effective 
change leadership. With the world of healthcare becoming more of a level playing field through the consolidation of providers, the ability to identify, understand, plan, and implement change initiatives will become a key area for competitive advantage.

Similarly, being unaware of, being indifferent to, or ignoring these barriers to change may result in competitive disadvantage and ultimate failure. On the basis of our study findings, we encourage hospital and healthcare executives and their leadership teams to address each question listed in Figure 2 the next time they approach a change initiative in their healthcare enterprise. The responses may play a significant role in determining the outcome of upcoming changes. And, as stated earlier, any change worth making is worth making right; to do otherwise is to create change in the wrong direction.

\section{[FIGURE 2 about here]}

\section{LIMITATIONS}

A primary limitation to this research study that might affect its generalizability is the small sample size of 167 frontline leader participants coming from only four Midwest communities. Small research samples may inherently include some degree of sample bias caused by the unique characteristics of each hospital, the unique characteristics of the study participants or geography, or other regional influences. However, the current healthcare climate is driving organizations across the United States to react to the same set of regulations and other challenges, which might help mitigate this issue. In the end, every effort was taken to accurately capture the input of this sample of frontline participants to provide the reader with a rich description of the factors that cause a hospital change or improvement initiative to fail or succeed. 


\section{REFERENCES}

American College of Healthcare Executives (ACHE). (2011), Top issues confronting hospitals: 2010. Healthcare Executive, 26(2), 100.

Bazzoli, G., Dynan, L., Burns, L. R., \& Yap, C. (2004). Two decades of organizational change in health care: What have we learned? Medical Care Research and Review, 61(3), 247-331.

Capoccia, V. A., \& Abeles, J. C. (2006). A question of leadership: In what ways has the challenges of improving health and health care informed your understanding and practice of leadership? Leadership in Action, 26(1), 12-13.

Cunningham, C. E., Woodward, C. A., Shannon, H. S., MacIntosh, J., Lendrum, B., Rosenbloom, D., \& Brown, J. (2002). Readiness for organizational change: A longitudinal study of workplace, psychological and behavioural correlates. Journal of Occupational and Organizational Psychology, 75, $377-392$.

Dye, C. (2010). Leadership in healthcare: Essential values and skills. Chicago, IL: Health Administration Press.

Kotter, J. (1995). Leading change: Why transformation efforts fail. Harvard Business Review, 93(2), 59-67.

Longenecker, C. O., \& Simonetti, J. A. (2001). Getting results: Five absolutes for high performance. San Francisco, CA: Jossey-Bass.

Longenecker, C. O., Papp, G. R., \& Stansfield, T. C. (2007). The two-minute drill: Lessons for rapid organizational improvement from America's greatest game. San Francisco, CA: Jossey-Bass.

Longenecker, C. O., Papp, G. R., \& Stansfield, T. C. (2009). Quarterbacking real and rapid organizational improvement. Leader-to-Leader, 51(Winter), 17-23.

McAlearney, A. S. (2010). Executive leadership development in U.S. health systems. Journal of Healthcare Management, 55(3), 206-222. 
FIGURE 1

Top 10 Barriers to Successful Hospital Change as Identified by Frontline Hospital Leaders*

1. Poor implementation planning and overly aggressive timelines $\quad 73 \%$

2. Failing to create buy-in/ownership of the initiative $67 \%$

3. Ineffective leadership and lack of trust in upper management $62 \%$

4. Failing to create a realistic plan or improvement process $55 \%$

5. Ineffective and one-way communications $\quad 52 \%$

6. A weak case for change, unclear focus, and unclear desired outcomes $50 \%$

7. Little or no teamwork or cooperation $43 \%$

8. Failing to provide ongoing measurement, feedback, and accountability $38 \%$

9. Unclear roles, goals, and performance expectations $36 \%$

10. Lack of time, resources, and upper-management support $33 \%$

*The findings presented in this exhibit are from a sample of 167 frontline leaders from four Midwest community hospitals who participated in 42 focus groups designed to identify the primary causes of why hospital change initiatives fail to achieve desired outcomes. The percentages represent the number of focus groups, out of 42 , that identified a specific factor. 
FIGURE 2

A Healthcare Leader's Change Checklist

When approaching a change and improvement effort, do our leaders ...

1. Take the time to develop an effective and realistic implementation plan with realistic timelines?

2. Make it a high priority to create buy-in and ownership with the people who are responsible for implementing the plan?

3. Lead by example and demonstrate both competency and character?

4. Create realistic and effective action plans and processes when performance improvement is needed?

5. Practice effective two-way communication to ensure that people understand the message and that their concerns, needs, and expectations are understood?

6. Make a compelling case for change, create a clear focus, and specifically identify desired performance outcomes?

7. Make it a priority to develop the teamwork and cooperation necessary to support a desired change or improvement initiative?

8. Provide ongoing measurement, feedback, and accountability for every change initiative they are responsible for leading?

9. Clarify the roles, goals, and performance expectations for each individual involved in the change improvement effort?

10. Provide people with the additional time, resources, and support necessary to create real change in performance improvement? 